\title{
The phonesthetics of blends: A lexicographic study of cognitive blends in the OED
}

\author{
Chris Smith \\ CRISCO Université de Caen
}

\begin{abstract}
This preliminary study of 285 morphological and cognitive blends (attestation dates 1200-2012) aims to investigate the role of phonesthemes in the structuring of the English lexicon. A study of OED word origins shows a disparity between older (1200-1900) and recent blends (1903-2012). Sound symbolism plays an overriding role in over $50 \%$ of older blends, leading to a study of initial phonesthemes (i.e. consonant clusters). Several case studies of diachronic semantic shift attested in the OED point to the existence of multidirectional motivation ties. This preliminary study supports the psycholinguistic theory that 1) there is a structured secondary sound symbolism in English, and that 2) it is still productive today and may play a role in the creation of neologisms as well as ensuring their survival (see Bergen, 2010: 52). A more in-depth usage-based analysis using sophisticated measurement tools is the next step in the study.
\end{abstract}

Key words: cognitive blends; the $O E D$; diachronic semantic shift; multidirectional remotivation; phonesthemes.

\section{Introduction}

Phonesthemes, i.e. 'sub-morphemic unit[s] that ha[ve] a predictable effect on the meaning of a word as a whole' (Otis \& Sagi, 2008: 65) are having a moment thanks to novel cognitive and pycholinguistic perspectives (Bergen, 2004, 2010; Drellishak, 2006 ; Otis \& Sagi, 2008). It has been suggested by Bauer (1983: 235) that the preservation of initial consonant clusters, in other words initial phonesthemes, plays a role in determining the structure of short blend outputs. This preliminary study seeks to determine if - and to what extent - blends have a phonesthetic structure. This paper attempts to provide answers to longstanding questions regarding the linguistic status of phonesthemes, such as:

A) Is there a correlation between phonesthetic structure and blend longevity? In other words, is there evidence of phonesthetic structure in both older and recent blends? 
B) Is there lexicographic evidence of the existence of phonesthemes? Where do phonesthemes originate from, and how do they behave diachronically? Is phonesthetic attraction verifiable lexicographically?

Going against the grain of current empirical research in lexical semantics, the chosen methodology is a lexicographic study of 285 blends, selected from literature, including contested cognitive blends (a full list is provided in Appendix B) ${ }^{1}$. A first step in answering A) consists in analysing the $O E D$ 's labelling of blends, and presenting the results to compare the structure of older and recent blends. With a view to answering B), a second step follows up by analysing phonesthetic reanalysis in older blends, before attempting to extrapolate potential remotivation in recent blends.

The structure of this paper follows 4 parts. Part 1 lays out the groundwork regarding the typology of morphological blends and argues for the crucial inclusion of cognitive blends ${ }^{2}$ in light of the proposed relevance of phonestheme preservation in the blend output. Part 2 provides a brief discussion of the impact of the evidence of psycholinguistic reality of phonemes for the ongoing debate on the linguistic status of phonesthemes and presents the methodology for determining the role of phonesthemes in blend structure. Part 3 then presents the data compiled regarding the structure of blends in the OED, showing that over $50 \%$ of older blends are phonesthetic in structure, compared to barely $2 \%$ of recent blends. Several lexicographic case studies of diachronic shift in historical blends provide solid evidence of analogical remotivation of blends based on phonesthetic reanalysis. Extrapolation of the multidirectional motivation ties to novel cognitive blends provides predictions of potential future semantic shift. Part 4 concludes that this preliminary study shows evidence of multidirectional motivation in cognitive blends in the $O E D$, and paves the way for further research into the role of phonesthetic reanalysis in the organisation of the lexicon.

\footnotetext{
${ }^{1}$ Choosing a lexicographic study over a corpus-driven study is motivated by constraints of time and of technique. The aim here is not to deliver an in-depth study but to consider the possibility of devising a way to test the theory of phonestic attraction, i.e. whether phonesthemes structure the lexicon. The question of how to measure this must be left to further study.

${ }^{2}$ A cognitive blend is defined as 'one word which delivers the concept of two base words' (Bat-El 2006: 66). The implication is that any ambiguity regarding definitive input words does not result in disqualification of the output as a blend.
} 


\section{Blend outputs}

\subsection{Brief typology of morphological blends}

Blending is a word formation process akin to compounding and clipping. Blends are described morphologically as combining two input forms ${ }^{3}$ to produce a shorter output form. This means that segmental material from the source words is clipped to allow for a reduction of length of the output form. As Gries (2004: 416) points out, protoypical blends usually contain back-clipped source word 1 followed by foreclipped source word 2, leading to a portmanteau, an amalgam, or a telescoping of the two source words (henceforth abbreviated to 'sw') (see Quinion, 1996; Pound, 1914; Bauer, 1983).

Such canonical blends are words like skort(s) [1951] (skirt $\mathrm{x}$ short(s)), glamping [2008] (glamour $x$ camping), pleather [1982] (plastic $x$ leather), prissy [1842] (prim $x$ sissy), cankle [2002] (calf $x$ ankle) and of course the ubiquitous spam [1937] (spiced $x$ ham), and smog [1884] (smoke $x$ fog) which has spawned similar blends like smaze [1953] (smoke $\mathrm{x}$ haze) and vog [1987] (volcano $\mathrm{x}$ smog). Blends such as these tend to feature the clipping of an overlapping segment as in glamping where -am is shared by both source words, or pleather where -1 is shared by both sw.

Another type of blend features one fully recognizable source word: either sw1 has it full form: webzine (web $\mathrm{x}$ magazine), gaydar [1988] (gay $\mathrm{x}$ radar), tankini [1985] (tank $x$ bikini), prisonscape (prison $x$ landscape), and bromance [2004] (bro $x$ romance). Occasionally sw2 is full as in cankle, frenemy [1953] (friend $x$ enemy). In some cases, both sw1 and sw2 are fully retrievable due to haplology (overlapping segment), as in glamazon [c1960] (glamour x amazon), swaption [1988] (swap x option), or bacne [2003] (back $x$ acne).

There is also a third and fourth type of blend output. The third type involves analogical patterning, whereby the clipped sw2 becomes suffix-like, as in walkathon [1930] (walk $x$ marathon), telethon [1930] (television $x$ marathon), talkathon [1934] (talk x marathon), or -athon, -alicious, -scape, -kini, -ercise, -moon, -aholic, umentary, etc. These forms are called splinter compounds. Once a blend is formed, copycat blends occur naturally (see Bauer (1983: 104) and Benczes (2010: 232) on splinter formation; Lehrer, 2007 ; Miller, 2014; see Szymanek (2005: 431) on the relation between analogy and high productivity). Historically there is usually a first blend; prisonscape [1796] is cited as the first in a pattern of blending (seascape [1799], cityscape [1857], moonscape [1907] manscape [1927]). It is notable that splinters occurring in a prefix position do not appear to pose the same problems, as the output is still

\footnotetext{
3 Or occasionally more than two (as in droodle [1953 Wiki] (drawing $\mathrm{x}$ riddle $\mathrm{x}$ doodle), contraption [1825] (contrivance $\mathrm{x}$ trap $\mathrm{x}$ conception), snooze [1789] (sleep $\mathrm{x}$ nap $\mathrm{x}$ doze)), flaunt [1566] (fly, flout $\mathrm{x}$ vaunt).
} 
viewed as a blend (man- as in manorexia [n/a] (man $\mathrm{x}$ anorexia), faux- as in fauxmance [2008] (faux $x$ romance), sham- as in shamateur [1896] (sham $x$ amateur), mock as in mocktail [1936] (mock $\mathrm{x}$ cocktail) etc.). As for the final type, these are double clipped words (sitcom [1964] (situation x comedy), misper [1994] (missing x person), hazmat [1980] (hazardous $\mathrm{x}$ material), cyborg [1960] (cyber $\mathrm{x}$ organism), etc.) which are generally viewed as non blends, and are therefore excluded here (see Plag 2003).

Blending appears limitlessly creative, but counterexamples (such as *brench (Kelly, 1998) or *breakfunch (Gries, 2004) rather than brunch) illustrate the existence of constraints. However, the nature of these constraints remains somewhat questionable. Gries (2004: 427) concludes that stress pattern preservation is overriding: 'similarity motivated preservation of one source word's stress pattern [is] considered more important than the recognizability-motivated preservation of letters and phonemes.' Miller (2014: 203) argues convincingly for the importance of metrical structure. At the heart of the issue lies 'the compositional transparency of the output' (Miller, 2014: 204). The length of the blend itself is a factor in this, as longer blends and shorter blends have different templates, see Miller (2014). Blends such as smog, brunch [1896] (breakfast $\mathrm{x}$ lunch), bit [1848] (binary $\mathrm{x}$ digit), goon (gorilla $\mathrm{x}$ baboon) (cited in Bat-El, 2006) retain very little material from their source words. The fact is that shorter blends tend to be more opaque. The consensus is that short monosyllabic blends preserve the onset of source word 1 and the rhyme of source word 2 (see Bat-El (2006: 69) and Gries (2004: 427)). Bat-El (2006: 69) argues that rhyme/coda preservation explains why slosh [1808] (slop $\mathrm{x}$ slush) is preferred over *slush and boost [1815] (boom $x$ hoist) is preferred over *boist. Although this conclusion does not satisfactorily explain word order and switch point, it seems that the preservation of initial consonant clusters may be crucial in such short blends (see Bauer 1983: 235). I propose to test the hypothesis that the preservation of submorphemes, or more specifically phonesthemes, may account for preferred forms of blends.

\subsection{Cognitive blends}

Shorter blends such as slosh and boost exhibit little material from sw1 and sw2, and consequently are less transparent. The blend motel [1925] (motor $\mathrm{x}$ hotel) is recognizable thanks to the stress pattern of sw2. The retrievability of sw1 motor from the phoneme $/ \mathrm{m} /$ however is no doubt contextual and cultural. If one compares motel with the blend moobs [1990] (man/male $\mathrm{x}$ boobs) the retrievability of sw1 from the phoneme $/ \mathrm{m}$ / is entirely different, for semantic reasons ( ${ }^{*}$ motor boobs would make no sense). Meld [1936] (melt $x$ weld) is yet another example for a different interpretation of the $[\mathrm{m}]$ sound. This lack of transparency can affect recent creative blends, such as vook [2009] (video $\mathrm{x}$ book), choup [2007] (chowder $\mathrm{x}$ soup), swacket [n/a] 
(sweater $\mathrm{x}$ jacket), or wogging [2008] (walk $\mathrm{x}$ jogging), but also long-term lexicalized historical blends, suggesting that the retrieval of source words is no longer needed for interpretation: electrocution [1889] (electric x execution), dextrose [1869] (dextrorotary $\mathrm{x}$ glucose), bionics [1960] (biology x electronics).

Despite many documented instances of creative short-lived blends (see Lehrer (2007) for recent formations, Bragdon (2008) for historical blends), some blends on the other hand have proven to be highly stable. Such historical blends include words such as prance [1380] (proud $x$ dance), splutter [1677] (splatter $x$ sputter), flurry [1698] (flaw $x$ hurry), swipe [1829] (sweep $x$ wipe). The nature of these blends is qualified as indefinite by Louise Pound (1914), because the source words are unclear, and even possibly multiple. The OED rarely confirms the blend status of these expressions. Instead, the labels provided range from onomatopoeic (flurry), echoic or imitative (splutter), alterations or variants (swipe), unknown origin (prance), to even arbitrary or 'factitious' (snivelization [1849] (snivel $x$ civilization), chortle [1871] (chuckle x snort) and even humongous [1967] (huge x monstrous). Occasionally, the OED conjectures several origin hypotheses in the absence of unequivocal evidence. A case in point is the verb flounder [1592] (founder $x$ blunder ${ }^{4}$ ). In view of its obscure etymology, the $O E D$ concedes that it may be an onomatopoeic blending of various earlier words, such as flounder and blunder 'and the various other verbs in $f$ - expressing impetuous and clumsy movement'. However, the $O E D$ shows no systematic differentiation between blends, onomatopoeic formations, analogical formations or alterations and variants. For instance the noun glob [1900] is given both as a potential blend (gob $\times$ blob) and as a possible clip of globule. The word slosh [1808], cited by Bat-El (2006) as a blend, is given as 'imitative' based on the noun slush $^{5}$ [1642]. Equally, the adjective boldacious [1845] (bold $x$ audacious) is not labelled blend, but rather a 'combination' of the adjectives bold and audacious. A further illustration is contraption [1825] (contrivance $\mathrm{x}$ trap $\mathrm{x}$ conception) which is called a popular formation based on contrive 'with some vague association with trap', or doldrum [1812] (dull x tantrum) which is viewed as a 'derivative' of dold, to be compared with tantrum.

The conclusion to be drawn here is the observation that the lexicographic use of the label 'blend' is problematic. In particular, the OED shows a degree of reluctance in using the label for non-specific blends, where source words are indefinite. Instead the OED resorts to referring to labels such as 'association', 'derivation', 'imitative', 'echoic', 'onomatopoeic blending', and so on.

In spite of the highly contested nature of these historical formations, this paper views blends as a cognitive formation. A cognitive blend can be defined as any word that can be interpreted as combining the meaning of two source words, as

\footnotetext{
4 See Pound (1914: 54)

5 Slush [1642], noun, is labelled in OED as being 'of doubtful origin: compare sludge $\mathrm{n}$. and slutch $\mathrm{n}$. (both from the 17th cent.) and the more recent slosh n'.
} 
per Bat-El's (2006: 66) definition of a blend: 'one word that delivers the concept of its two base words'. The noun and adjective greige [1835] shows evidence of being interpreted as a blend of (grey $x$ beige), in blatant contradiction with its etymological origins (from the French grège). The OED entry for greige states that the sense of the noun evolved around 1911 to 'a colour between beige and grey, similar to that of undyed or unbleached fabric'; the adjective greige also shows parallel semantic shift around 1925. A corpus SketchEngine co-occurrence analysis of greige confirms these findings, resulting in a high incidence of greige used in the sense 'greenish taupe', i.e. green/grey $x$ beige. The OED accepts that words like muppet [1959] (marionnette x puppet) and slurb [1962] (slum x suburb) are likely reanalysised as blends post attestation. This a posteriori reanalysis, also called folk etymology (see Fill (2004)), is in fact a sign of bidirectional motivation, whereby cognitive word associations motivate reanalysis as blends (see Umbreit (2010) on bidirectional motivation in $\mathrm{N} / \mathrm{V}$ conversion pairs). It therefore makes sense to take into consideration all blends, both morphological blends and cognitive. The appendix of blends presented in this paper (Appendix B) provides the list of 285 blends compiled from the literature on blending (Pound, 1914; Plag, 2003; Gries 2004; Lehrer, 2007; Bragdon, 2008; Miller, 2014) and gives source words provided by said literature, regardless of $O E D$ labelling and lack of consensus.

\section{Blends and phonesthemes}

\subsection{Psycholinguistic breakthrough into phonesthemes}

One of the main concerns of critics of phonestheme theory is that phonesthemes are non-systematic and non-compositional. Since they are sporadic in nature (see Hock and Joseph 2009), they cannot be identified by traditional semantic analysis methods (i.e. listing of necessary conditions), making them nothing more than a conjecture. A second criticism levelled against phonesthemes is that they are not supported by etymological lineage. A third criticism is that the whole notion of phonesthemes is flawed as pertaining to a subjectivist mentalist approach to language. They are impressionistic and no clear definitive set of semantic features has been described to account for the sense of these sound clusters. (See Bottineau (2008) for a full account of the discussion).

In the face of such scepticism, recent cognitive and psycholinguistic research has by and large revolutionised the perspective on phonesthemes. Firstly, experimental research has shown the significance of phonesthemes in that they statistically occur more frequently than chance. Bergen's (2004) priming experiments, and further statistical studies (Otis \& Sagi, 2008) have shown that phonesthemes indubitably affect lexical processing speed and reliability, thereby establishing them as 
a subject worthy of study. Bergen (2004: 307) concludes that his findings show that '[p]honaesthemes are a testament to the diligence of the human ability to encode and use subtle statistical associations in the linguistic environment.' These results are supported by neurolinguistic science, and in particular the role of phonological neighbourhood density (Luce \& Pisoni 1998) which acts as a facilitator of lexical access. Phonological word neighbours are defined as subsets forming minimal pairs, much like phonesthetic attraction networks. Martin (2007: 30) attributes the feedback loop process to the phonological neighbourhood effect.

Bergen (2004: 307) argues that phonesthemes have a snowballing effect, leading to a feedback loop of form-meaning pairings, i.e. bidirectional motivation. This accretional effect is thought, as suggested by Bergen (2004: 290), to eventially lead to the 'extension over time' of phonestheme clusters (also see Pinker (1997: 300), Miller (2014: 886), Waugh (1994: 67)). These cognitive and psycholinguistic advances have been empirically validated by computational statistical research (Drellishak, 2006; Otis \& Sagi, 2008; Boussidan et al, 2009; Abramova et al, 2013). Natural language processing techniques have been used successfully to more adequately and precisely analyse the semantic behaviour of target words using contexonyms, i.e. frequently occurring words in context. Such techniques have been used by Drellishak (2006) to test whether phonesthemes exhibit frequency patterns above significance levels, and to study the semantic content of the conjectured phonesthemes (see Abramova et al. 2013 on automatic labelling of phonesthemic senses, and Boussidan et al. 2009, for a statistical study of the semantics of phonesthemes).

As for the second criticism regarding lineage, the consensus on phonestheme requirements is actually that there should be no correlation between a phonestheme and a shared root. Bergen (2004) and Drellishak's (2006) definitions of phonesthemes are specifically based on this criterion. However, Otis and Sagi (2008: 36) argue that the meaning of phonesthemes is compatible with competing factors, lineage and reanalysis.

There are two possible factors that might explain the relationship between phonaesthemes and word meaning - the historical root of the words, and cognitive processes that relate phonetic and semantic similarity. Importantly, these hypotheses are not mutually exclusive. Otis and Sagi (2008: 36).

This position is backed by Boussidan et al (2009: 36), who note that some meaningful morpho-phonological clusters 'may have survived through generations and formed the basis for phonesthemes'. On the issue of phonestheme etyma, Bolinger (1965: 224) also took the view that while some phonesthemes may originate from a common root, further 'more or less accidental' resemblance continues to cause

\footnotetext{
${ }^{6}$ Miller (2014: 88) argues that "[a]nalogy, then, is not a separate type of word formation but is rather the means by which word creation originates and spreads".
} 
convergence. ${ }^{7}$ Anecdotal evidence of reanalysis is observed in Reay (2009: 897). Reay 2009 describes how phonesthemes can arise out of loan words, providing evidence that they override etymological motivation. The loan words slalom [1921] originates from Norwegian slalåm, < sla sloping + låm track, but is re-analysed as containing / sl/ sliding movement (already present it would seem in the cognate). The adjective cushy [1915] from Anglo-Indian, <Hindi ḳhūsh pleasant is reanalysed as containing the submorpheme $<\mathrm{cu}>$, injecting the notion of "comfortable, soft, cuddly" as in cushion. Reay's examples thereby show lexical evidence of Bergen's priming effect. Further promising research has examined the historical origins and development of phonesthemes (Philps, 2008a and 2008b), whereas further research focuses on co-occurrence patterns to study the semantic shift in phonesthetic words (Smith, forthcoming).

The third argument regarding the lack of consistency in phonesthemes is more delicate. Identifying an objective and universal value has shown to be challenging. One single sense of value does not necessarily hold for all words carrying a particular sound cluster. The reason for this, as argued by Bergen (2004: 290), is that phonesthemes are not compositional in nature, i.e. they do not follow traditional building-block rules. Furthermore, at the heart of the problem lies the theoretical foundation for sound symbolism. It has traditionally been suggested that meaning is notional (see Tournier 2007, Bolinger 1950), but new linguistic approaches have proposed that phonesthemes are triggers of modal mental representations or schemas (see Argoud (2008), (2010); Albrespit (2007), or sensori-motor subactions (Bottineau, 2008: 29). What is empirically crucial here is the fact that it appears that one phonestheme may be associated with not one but several mental schemas or associations. For instance Miller (2014: 200) explains that initial sl- has four associations - a) fluid motion, b) messy liquid, c) improper, d) violence. Each association is illustrated by a set of synonymous sl-words, each constituting a phonesthetic attraction set. Similarly, Bottineau (2008: 31) notes that /skr/ may have resulted from 'two merging strains, $s k+r$ (surface + agentivity: scrub, scroll, scratch) and the scr- onomatopœia (screech, shrill).' Philps (2008a; 2008b) confirms that there are likely several offshoots, both related to historical etyma and to the evolving lexicon. Since this theoretical issue is complex and remains controversial, this paper will not enter into the debate here.

While these new perspectives can put to rest two of the main objections to phonesthemes, much remains to be uncovered about their linguistic status and semantics. Briefly put, do phonesthemes only exist in the mental lexicon? Is there lexical evidence that phonestheme constellations 'giv[e] rise to the status of organ-

\footnotetext{
7 [T] he tracing of constellations is of special interest in English. The language is almost totally lacking in an orderly system of derivatives. Words like comparable and impious are turned so as to show no connection with cognates. [...] If the language is settling into a species of interrelationship, it is probably highly time. Bolinger (1965: 202).
} 
izing structures in the lexicon, on the basis of their frequency', as claimed by Bergen (2004: 291)? Furthermore, how is phonesthetic attraction to be measured?

\subsection{Position, proposal and methodology}

As a non-morphemic word formation process, blending is undeniably difficult to pin down. This paper seeks to test lexicographically the hypothesis that phonesthemes play an organisational systemic role in the semantics of blends in English. The approach is lexicographic, based on a sample corpus of 285 blends dating from 1200 to 2012. With this in mind, a list of blends, including contested cognitive blends, have been compiled from existing literature (Pound, 1914; Lehrer, 2007; Bat-El, 2006; Miller, 2014) and the OED (3rd edition). For each proposed blend, the first recorded date of attestation is noted, the conjectured (and sometimes contested) source words are given. This information is then cross-checked with the OED's etymological information. A separation between 2 sub-corpora based on the date of first attestation of the blend was then made. The cut-off point to the modern era was set post 1900, motivated by two main reasons. Firstly, there are fewer older blends than recent blends for obvious reasons of availability of data, and also due to the obsolescence factor. Secondly, the modern age teems with creative morophological blends (see Ayto, 1999 ; Gries, 2004 ; Lehrer, 2007).

- The first step is to compare etymological status of blends with dates of first attestation. A classification of blends according to etymological status and dates is carried out. Observations regarding the status and nature of older blends and novel blends are then laid out.

- The second step is to test the theory of phonesthetic attraction on the corpus of older blends. To achieve this, I propose to track semantic shift in several case studies, and consider the evidence of phonesthetic reanalysis. On the basis of the results, predictions are then made regarding the phonesthetic reanalysis of novel blends.

\section{Results and discussion}

\subsection{Classification of blends}

The size of the corpus compiled is modest compared to other blend corpora (988 in Gries (2004), given the decision to use a lexicographic corpus as opposed to a usage-based corpus. The objective of this preliminary study explains this choice: the purpose is to test heuristically the theory that phonesthemes structure the lexicon. 
The diachronic perspective also places a constraint on the blends that are selected, as they must be both non-obsolete and lexicalized (or of frequent use).

Figure 1 below shows the etymological treatment and labelling of the 285 blends in Appendix B. For each era (1200-1900 and 1903-2012), a percentage is given for each label or subtype provided by the $O E D$ or secondary sources: blend, onomatopoeic, arbitrary, alteration or variant, combining form, unlisted, unknown, loan.

There are two major differences between the data pertaining to older blends and that pertaining to recent or novel blends. Firstly, the overwhelming majority of blends 1200-1900 are sound symbolic compared to a very small number of recent blends. Conversely, an overwhelming majority of recent blends are labelled as unequivocal blends, while another large proportion are recent coinages that, unsurprisingly, remain unlisted in the $O E D, 8$ such as vook [2009] (video $x$ book), tottle [n/a] (top $\mathrm{x}$ bottle). The data is presented contrastively in Figure 1 (blue represents 1200-1900 blends, red represents blends post 1900): it brings to the fore the major discrepancies between older and recent blends in terms of their lexicographical treatment in the OED.

\section{Blend origins according to the OED}

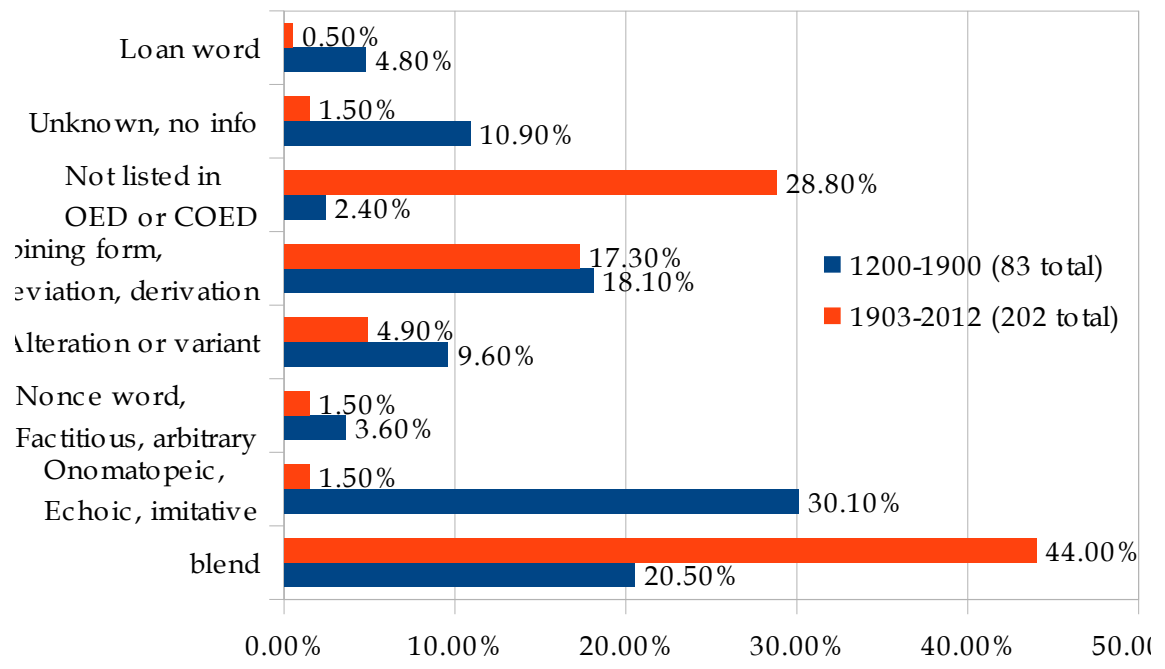

Figure 1. Comparative view of blend origins 1200-1900 vs 1903-2012.

${ }^{8}$ See Appendix B for full list of blends. 
As could be expected, the label blend is more readily used for recent blends $(44 \%)$ than for older blends, which are very rarely acknowledged as such by the $O E D$. The second major difference concerns sound symbolic forms: while $30 \%$ of older blends are labelled sound symbolic, a mere handful $(1.5 \%)$ of recent blends are thought to be so. Other categories ("unlisted/unknown") show some variation. There is one category that remains remarkably constant over time: a little under $20 \%$ are equated with compounds or derivation.

\subsection{Blends 1200-1900}

There are a total of 83 blends in the 1200-1900 subcorpus. Of these, I have identified $46(55 \%)$ that can be analysed in terms of their sound symbolic structure. Appendix A gives [onset+rhyme] structure of monosyllables and disyllables (42 in total), following Bat-El (2006) and Gries (2004). Semantically and phonetically words, i.e. words belonging to the phonesthetic network, are also provided for each blend in a $4^{\text {th }}$ column. The 4 remaining plurisyllabic words have not been listed (flabbergast [1772], cantankerous [1736], blatterature [1512], snivelization [1849]) as they are more complex and cannot be analysed by [onset+rhyme] structure alone.

The initial clusters occurring in the blends in Appendix A have been classified in Table 1 (below) in decreasing order of frequency (number of occurrences in the blend data). These clusters are cross-referenced with existing verified initial phonesthemes and their suggested core values in the final column, using both Tournier (2007) and Drellishak (2006).

Table 1. Frequency of initial phonesthemes in 42 out of 83 blends 1200-1900.

\begin{tabular}{|l|l|l|l|}
\hline $\begin{array}{c}\text { Initial } \\
\text { C }\end{array}$ & $\begin{array}{c}\text { Raw } \\
\text { frequency }\end{array}$ & \multicolumn{1}{|c|}{ Blends } & \multicolumn{1}{|c|}{ Core phonestheme semantics } \\
\hline fl- & 8 & $\begin{array}{l}\text { flaunt, flounder, flurry, flush, } \\
\text { flare, flustrate, fluff, flimmer, }\end{array}$ & $\begin{array}{l}\text { Motion, repeated or fluid (Drellishak) } \\
\text { surface flow (Tournier) }\end{array}$ \\
\hline b- & 4 & bumble, bash, boost, burble & $\begin{array}{l}\text { Dull impact (de Cuypere 2008: 113) } \\
\text { sound of a voice, muted explosion } \\
\text { (Tournier) }\end{array}$ \\
\hline sm- & 3 & smash, smarm, smog & $\begin{array}{l}\text { Insulting, pejorative term (Drellishak) } \\
\text { Taintedness (Tournier) }\end{array}$ \\
\hline sn- & 3 & sniggle, snark, snooze & $\begin{array}{l}\text { Nose ; snobbish (Drellishak) } \\
\text { region of the nose (Tournier) }\end{array}$ \\
\hline squ- & 3 & squish, squiggle, squirl & Soft spongy compressed (Drellishak) \\
\hline
\end{tabular}




\begin{tabular}{|c|c|c|c|}
\hline tw- & 3 & twirl, twizzle, twiddle & $\begin{array}{l}\text { Turn; distort (Drellishak) } \\
\text { Slight torsion (Tournier) }\end{array}$ \\
\hline scr- & 3 & scrouge, scrunch, scrumptious & $\begin{array}{l}\text { Sound, irregular movement } \\
\text { (Drellishak) } \\
\text { Confusion, messiness (Tournier) }\end{array}$ \\
\hline bl- & 2 & blotch, blurt & $\begin{array}{l}\text { Breathing, swelling (Tournier) } \\
\text { blow swell inflate (Drellishak) }\end{array}$ \\
\hline gl-9 & 2 & glaze, glob & $\begin{array}{l}\text { Light; vision (Drellishak) } \\
\text { Light reflection smooth surface } \\
\text { (Tournier) }\end{array}$ \\
\hline sw- & 2 & swipe, swizzle & $\begin{array}{l}\text { Move rhythmically Drellishak } \\
\text { To and fro oscillation (Tournier) }\end{array}$ \\
\hline sl- & 2 & slosh, slithy & $\begin{array}{l}\text { Slowness, sloth (Tournier) } \\
\text { sl-attack and sl-sliding movement } \\
\text { (Reay 2009) }\end{array}$ \\
\hline gr- & 1 & grumble & $\begin{array}{l}\text { Deep or complaining noise (Drellishak) } \\
\text { grasping or grunting (Tournier) }\end{array}$ \\
\hline br- & 1 & brunch, & Fracture (Tournier) \\
\hline $\operatorname{tr}-$ & 1 & trudge & Walking (Tournier) \\
\hline $\begin{array}{l}\text { wh- } \\
\text { /thw- }\end{array}$ & 1 & whang, thwack & $\mathrm{N} / \mathrm{a}$ \\
\hline qu- & 1 & quag & $\mathrm{N} / \mathrm{a}$ \\
\hline ch- & 1 & chortle & $\mathrm{N} / \mathrm{a}$ \\
\hline m- & 1 & mimsy & $\mathrm{N} / \mathrm{a}$ \\
\hline
\end{tabular}

The most frequently occurring clusters in the sample (13 in total out of 17 onsets) coincide with established phonesthemes, as can be seen in Table 1. By far the most common in our corpus of blends is the $f$ - phonestheme, occurring a total of 8 times, followed by a whole range of double $C$ clusters occurring 3 or 4 times. All the words in Table 1 carry plausible associations with the core phonesthetic meanings (to some degree). As Bauer (1983: 235) proposed, the preservation of initial clusters is a factor in the form of the blend, which Table 1 does not invalidate. However, is the initial phonestheme in the blend a preservation of the onset of sw1, or is the phonestheme triggered in the resulting blend?

Let us discuss the case of flimmer [1880] (flicker $\mathrm{x}$ glimmer). The verb combines two synonymic source words relating to light and carrying verified initial phonesthemes fl- and gl-. The attestation dates of sw 1 flicker [1000] and sw2 glimmer

\footnotetext{
${ }^{9}$ Bolinger (1950: 131) identifies the form / gl/ 'as referring to 'visual phenomena'.
} 
[1400] do not contradict the blend hypothesis. The OED entry for flimmer gives the sense 'To burn unsteadily; to flicker', noting usage is rare. A possible explanation is that it was historically dispreferred over earlier glimmer [1400] in the sense of faint flickering light. This may be related to the preference of cluster $g l$ - specialising in reference to light, whereas $\mathrm{fl}$ - specialises in motion or repeated flow. It is noteworthy that glimmer [1400] underwent a semantic shift from the initial sense of 'To shine brightly; to glitter. Of the eyes: To flash', to [1483] to the 'weaker sense: To give a faint or intermittent light; to shine faintly'. Flicker [c1000] on the other hand initially had the literal sense of motion through air 'Of a bird: To flutter; to hover. occas. To flap the wings; to move by flapping the wings', and is only attested in [1608] as referring to intermittent light, which is arguably a metaphorical interpretation of the original meaning. On the other hand, some proposed blends carry initial phonesthemes which cannot be derived from the sw1, as with Lewis Carroll's snark [1879] possibly (snake $x$ shark), referring to an imaginary creature combining the features of a snake and a shark. Although there seems to be no correlation between sw1 snake and the sn- phonestheme, Carroll's snark could arguably be construed as having negative connotations directly linked to this onset. A possible cause for this, and a possible motivation in Carroll's coinage, is the analogy with the existing homonym snark v [1866], 'to snore, snort'; [1882] 'to find fault; nag'.

This is no undisputable proof of Bolinger's (1965: 243) theory that language shows an inevitable drift towards iconicity ('the accomodation of form to meaning and meaning to form'). Still, at the very least, the data in Table 1 show evidence of multidirectional motivation: the link between a word and its source is counterbalanced by analogical inferences. Finding systematic lexicographic evidence of phonesthetic reanalysis is a difficult task given the lack of unambiguous diachronic information available. Ultimately, individual case studies can do no more than pinpoint the complexity of word lineage, but a few selected case studies of phonesthetic networks may be able to show semantic evidence of analogical reanalysis based on phonesthetic attraction (see Hock and Joseph for the merits of this approach). From there, we hope that statistical semantic protocols can be devised to obtain more accurate data.

\subsection{Using the OED to track semantic shift in cognitive blends}

Measuring, quantifying or even documenting how phonesthemes affect semantic shift is a difficult task. If there is a mechanism of convergence towards a phonesthetic sense, one would expect semantic shift to occur under the influence of words belonging to a phonesthetic set or network (see Bergen 2004: 290). I thereby propose to trace lexicographic semantic shift in older blends presenting phonesthemes to observe whether phonesthetic reanalysis can be confirmed in case studies. 
Let me at this point address the methodological issue of using a lexicographic source in spite of the current collocational corpus-based research. The OED remains a unique source of information regarding the lexicon, and presents the additional benefit of being less time-consuming than the corpus-based method. As this study intends itself a preliminary investigation, it does not warrant a full-blown usage-based study, which would require a time-consuming time-sliced historical corpus. I remain fully aware of the lexicographic bias of the $O E D$ but consider it to be acceptable as a tool for the purpose of this limited study (see Allan 2011).

The data collected from the OED shows that semantic shift is prevalent in blends such as twiddle [1547] (twist $x$ fiddle), flush [1548] (flash/flare $x$ blush), bumble [1532] (bungle $x$ stumble) and blotch [1604] (blot $x$ splotch). The OED entry for the verb twiddle shows that the sense 'twist' occurs much later (120 years or so) than the date of first attestation. Initially, the sense of twiddle was 'to be busy with trifles', possibly through analogy with slightly earlier piddle [1545] and fiddle [1377], thus suggesting an association between the form -iddle and the notion of idleness or unimportance, and possibly related to the fingers. Later niddle [1808] and diddle [1806] attest to this. The sense 'rotate or turn' arises in 1676, by analogy with twirl [1598] according to the OED. Twirl is of obscure origin, with the OED giving the verb as either an alteration or tirl/ turl [1543] meaning 'to rotate, spin' after whirl [1290] 'to circle', or an imitative form. Most importantly here, the transformation tirl to twirl introduces the tw-phonestheme for the first time, whereas tirl itself would be a metathetic transformation from trill [1386].

These words sharing phonetic and semantic material form a network as represented in Figure 2, which can be described as the semantic genealogy of twiddle. Semantic shift appears to involve connections being made between members of the network. All of these senses can be related to the semantic makeup of the verb twiddle.

Figure 2 represents the motivation between the senses of the verb twiddle on the left and the senses of related words belonging to the phonesthetic network. The closest words directly linked to twiddle are potential source words twist, twirl and fiddle. The phonesthetic network of the verb twiddle may be extended even further than the words represented in Figure 2 (see Reay 2006 for an attempt to represent the intricacies of phonesthetic networks).

Similarly, the semantic shift documented in the OED for the verb flush (not represented) shows signs of phonesthetic reanalysis, leading to multidirectional motivation. Flush has two distinct entries in the OED [1300] and [1548]. According to the $O E D$, the meaning of flush is affected by the phonesthetic attraction of flash [1566], blush [1400], and flare (now obs) [1550]. These analogical ties are perceived as taking precedence over etymological connection with French flux or fluiss-, fluir to flow. Turning to the verb bumble [1532], a sound-meaning association is apparent with synonyms bungle [1530] and jumble [1529], all three notably attested around the same time period. The origins of the network are traced back in the $O E D$ to cognates in Danish, Swedish and Low German, all thought to be onomat- 
opoeic according to the OED. Figure 3 shows the multidirectional ties linking bumble with each of the members of the synonym network.

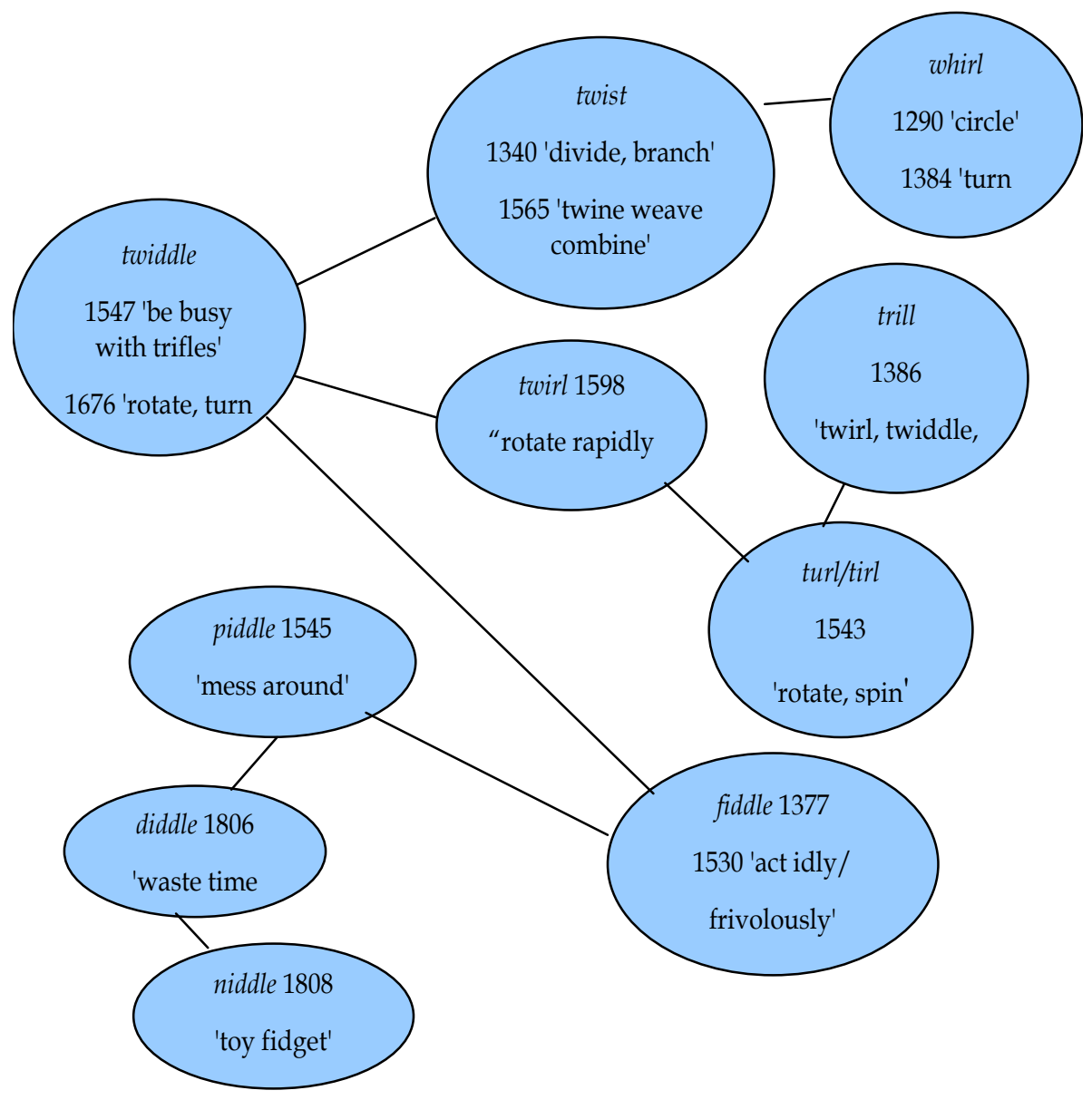

Figure 2. Phonesthetic network of twiddle.

As for the noun blotch [1604], the OED suggests the form originates from an alteration of the earlier blot [1400]. On further retracing the word lineage in the OED, plot is thought to have produced blot by modification of /p/ into /b/. It is possible, that this transformation of pl- into bl- might be motivated by the attraction of the bl- phonestheme, which has been validated empirically in Drellishak (2006), also 
listed in Tournier (2007), and studied by Argoud 2008.10 The second change, the evolution from -ot to -otch, -otch, leads to motivational ties with the now obsolete sense of botch [1400], originally meaning 'boil'. This conjecture is furthered by the fact that blotch is now the only word in the series or constellation (blotch-blot-botchplot) to have retained the sense "boil". Figure 4 shows the multidirectional ties between blotch and its synonym network.

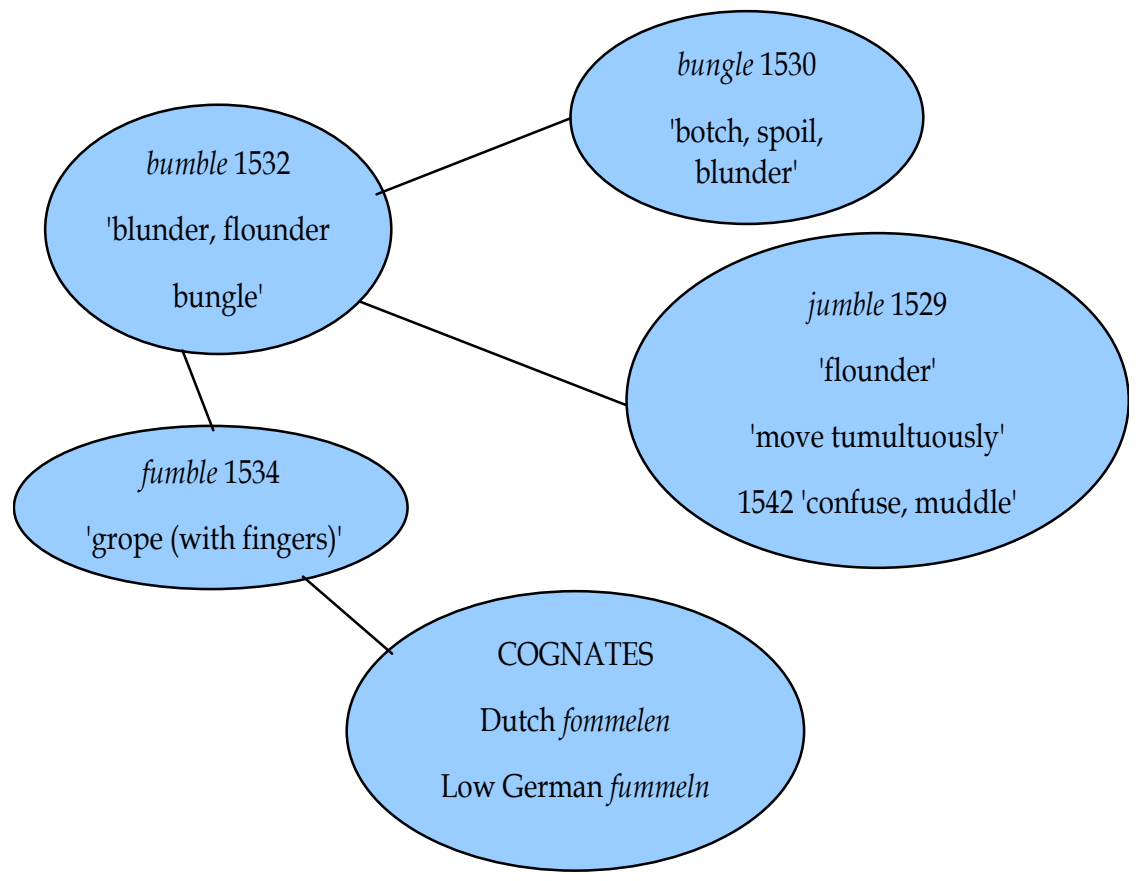

Figure 3. Phonesthetic network of bumble.

What these 4 case studies show is that lexicographic data indicates multidirectional motivation ties in the lexicon. The issue raised earlier with this method of enquiry is that the data is lexicographic rather than raw, and in that sense shows a possible bias on the part of the lexicographer rather than absolutely objective data. What can be said in spite of the flawed methodology is that there is evidence of retroactive semantic change can occur in an earlier word through association with a later form. For instance, the meaning of fluster [1422] (originally meaning 'excite') shifted around 1720, possibly under the influence of flustrate [1712] (in the sense 'flurry, confuse'), itself said to originate from a blend of (fluster $x$ frustrate). Under the effect of this synergy, the semantics of words within the network can adjust to

\footnotetext{
${ }^{10}$ It is notable that $/ \mathrm{bl} /$ is even mentioned by the $O E D$ in the entry for the verb blurt [1611], given as onomatopoeic, 'containing the $b l$ - element'.
} 
other members of the set. Thus there is increasing pressure of the phonestheme and increasing likelihood of further additions to the set. For instance, smog [1884] (smoke $\mathrm{x}$ fog) is likely affected by association with a strong phonesthetic network, with the sense 'pertaining to dirt or soiling'. Interestingly, the source word smoke does not belong to the network, but the attraction smear $\mathrm{v}$ [c825]; smudge $\mathrm{v}$ [1430], smut [1587], smirch $\mathrm{v}$ [1495], smatter [1386] is overriding. The strength of the phonesthetic attraction of sm- network is further attested in the verb smarm $v$ [1847] 'of obscure origin', according to the OED. The initial sense 'to smear, bedaub', later [1937] develops into the sense 'to slick, smooth down'. This development of the sense 'slick' is consistent with a reanalysis as a blend of (smear $\mathrm{x}$ charm).

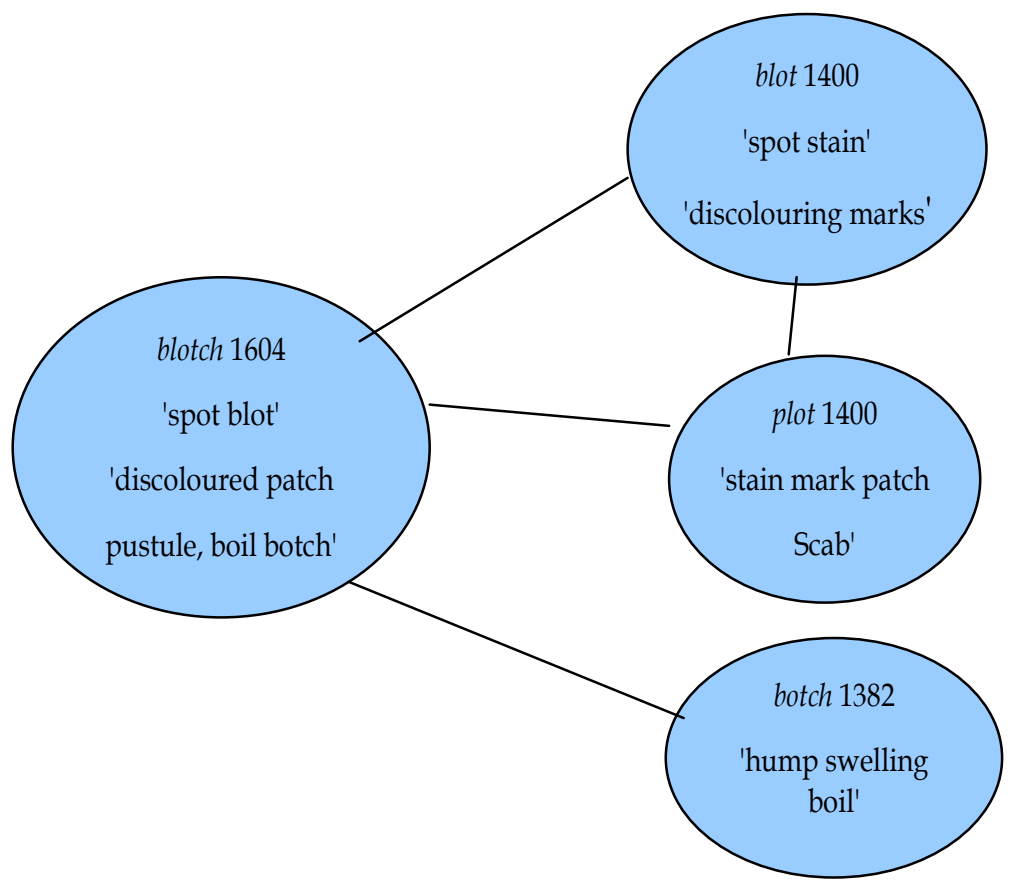

Figure 4. Phonesthetic network of blotch.

These lexicographic case studies attest to the sporadic existence of phonesthetic reanalysis in the lexicon. This is admittedly a far cry from providing unquestionable quantitive evidence of phonesthetic reanalysis in the English lexicon. However, as Hock and Joseph (2009) demonstrate, diachronic shift has been known to work through sporadic changes rather than frequent systematic change. Based on language change specialists such as Hock \& Joseph (2009), Joseph (2007), Miller (2014, 2010), I contend that marginal sporadic change is a valid language change process. 
These case studies based on the 1200-1900 blends corpus merely confirm the pertinence of such sporadic change. What remains is to develop a scientific objective methodology for quantifying the phenomenon in the lexicon.

\subsection{Extrapolating phonesthetic reanalysis in novel blends}

From the blend data available in our corpus (Figure 1), recent blends (1903-2012) are very marginally sound symbolic ( $1.5 \%$ out of 202 blends). And yet, on the basis of the attraction of sound symbolic networks, this does not preclude recent blends from undergoing similar sound-meaning feedback, or reanalysis. Remotivation (and multidirectional motivation) is a process of reanalysis or reinterpretation of a word (Fill, 2004: 1615). Loss of motivation is often a precursor to remotivation (Fill, 2004). In other words, when a word becomes less transparent semantically or/and morphologically (as is frequently the case for loan words), the likelihood of remotivation is greater.

In recent blends, the source words are generally still transparent and recoverable, which reduces the potential for remotivation. Nevertheless phonesthetic attraction may still play a role in semantic shift through reanalysis. A hypothesis based on the observations made concerning older blends is that sound symbolic clusters have a greater chance of being triggered if the length of the blend is one to two syllables (as in smarm, smog). In what follows, I will test the prediction for recent blend remotivation based on the corpus data.

Out of 202 recent formations, 39 (19.3\%) are monosyllabic, including words with a final syllabic /1/ (cankle, tottle, dongle, droodle) and those with a verbal -ing (wogging, sexting, vlogging) or -ed/-en (broasted). These arguably have the strongest potential for sound symbolic ground (all the phonesthetic blends are monosyllables or disyllables). Disyllables are also good candidates for remotivation, but only those that do not contain two clear-cut word splinters making them interpretable as compounds (such as tigon, sexploit, tweetheart, fanzine, twigloo, chillax) which are excluded from the count. This leaves 10 words: mingy, guppie, wussy, snuba, swaption, snitzy, swacket, craisin, snazzy, manny, bringing the total to 49 words out of 202 $(24.3 \%)$. The principle of phonesthetic attraction allows for prediction of sound symbolism in novel blends. Naturally, there are other extralinguistic factors involved; so predicting the precise evolution of a form is impossible. However, it may be possible to assess the potential for phonesthetic reanalysis on the basis of the diachronic change undergone by many blends 1200-1900. 2 basic conditions must be verified for remotivation: first, there must be a recognizable phonesthetic structure to the blend. Secondly, there must be some semantic compatibility. Table 2 shows the main initial phonesthemes with their corresponding meanings below (from Tournier 2007 and Drellishak 2006; also Argoud 2008 and 2010) when appropriate), and lists the 23 recent blends containing frequent initial phonesthemes. 
Table 2. Recent blends carrying recognizable initial phonesthemes.

\begin{tabular}{|l|l|l|}
\hline $\begin{array}{l}\text { Initial } \\
\text { phonestheme }\end{array}$ & Core sense & Blends \\
\hline sm & dirt & smaze smog smize \\
\hline sk & cover & skort \\
\hline b & dull sound & bonk \\
\hline bl & container & blurb bluff bleep bling blang \\
\hline dr & drag & droodle \\
\hline sp & sharp rejection & spam spim \\
\hline sl & sloth, slowness & slurb \\
\hline sn & nose & snazzy, snuba, snitzy \\
\hline spl & liquid sound & splog \\
\hline fl & surface flow & flub \\
\hline tw & torsion & twonk \\
\hline gl & light, vision & glamping \\
\hline
\end{tabular}

It is far more complex to formulate predictions for words which do not present statistically frequent initial phonesthemes. This is the case for words like tottle, cankle. droodle, vlog or vog, which do not present a highly conspicuous initial phonestheme (see Table 3).

Table 3. Recent blends without clear initial phonesthemes.

\begin{tabular}{|c|c|c|c|c|c|}
\hline t- & v/ vl- & m- & d- & cr- & w- \\
\hline tottle & vog/vlog & mingy & dongle & craisin & wussy \\
\hline & & manny & & & \\
\hline
\end{tabular}

The predictions of analogical remotivation or transfer for the words in Table 3 are more a matter of conjecture. However, there does seem to be ground for some possible phonesthetic attraction, based on the rhyme rather than the onset. For instance, the blend tottle [top+bottle] may become assimilated with a network of words relating to motion and (in)stability (Miller 2014: 194) such as totter [c.1200], titter [a1618], teeter [1843], didder [c.1420], dadder [1483], dodder [c.1600], topple [1542] and toddle [1568]. It remains to be verified if a semantic transfer occurs over time, giving tottle the meaning of a bottle that tottles or topples rather than a bottle that stands on its top. In a blend like cankle (referring to fat ankles), there is little reso- 
nance with a network of similar-sounding words in -ankle (ankle, rankle, possibly cantankerous). The verb rankle ('to fester') forms a minimal pair with the blend but apparently shares no common meaning and ankle is one of the source words of the blend. The association of an initial fortis velar / $\mathrm{k} /$ followed by an open back vowel and ending with a / $\mathrm{jk} /$ is suggestive of a pejorative force (Miller 2014). For Reay (2009: 896) 'the velar nasal / $\mathrm{y} /$ in final position denotes a resonant, longlasting sound. This final nasal also illustrates the synesthetic qualities of many phonesthemes, namely, the ability to denote nonauditory experience'.

Finally, the noun droodle [1953] (draw $x$ doodle $x$ riddle) is a Trademark name created by Roger Pryce to refer to a form of riddle or word game based on doodles or drawings. A droodle is basically a doodle containing a riddle. The term belongs to the $29,2 \%$ recent blends unlisted in the OED. Its status as an actual blend is unclear, it appears to be a conceptual blend, or so called nonsense word according to Wikipedia. Figure 8 represents the multidirectional motivation ties of the noun droodle creating a phonesthetic network.

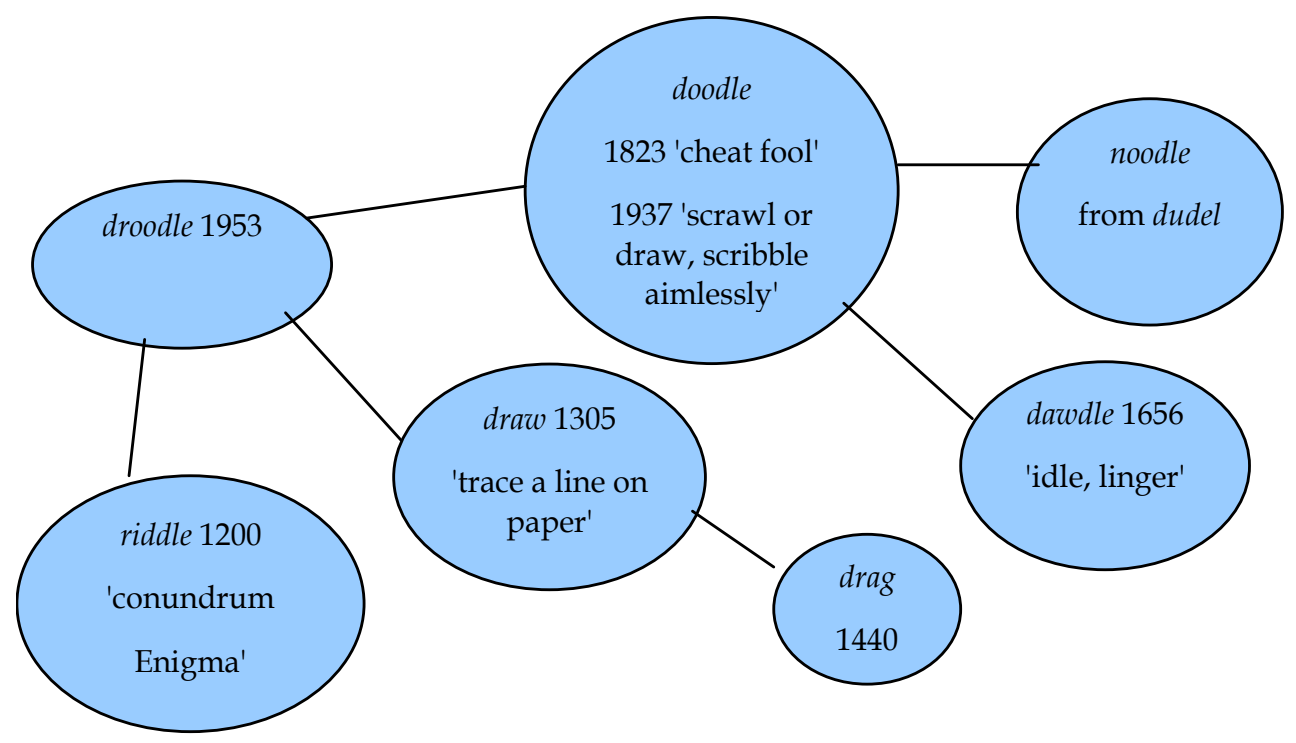

Figure 8. The phonesthetic network of droodle.

The $d r$ - phonestheme in draw and drag, is identified as having the sense of 'pulling down, languid' according to Drellishak (2006: 42) (see also Miller, 2014). The second tie is connected to -oodle/-awdle rhyme (in noodle, dawdle), which is arguably stronger and more specific (conveying the idea of idleness), with a higher correlation between form and meaning. However, in view of the infrequency of the term, 
no lexicographic evidence is available at this stage: out of 15 hits in the OEC, Sketch Engine results show significant co-occurrence with riddle, suggesting this connection significantly impacts on the meaning of the blend.

To conclude these case studies, it is quite clear that further study could benefit from a more wide-reaching corpus-analysis method.

\section{Conclusion: multidirectional motivation in cognitive blends in the $O E D$}

This diachronic lexicographic study has provided some preliminary answers to several questions surrounding blends and phonesthemes. The data collected show there is difference between older blends (i.e. blends that have been in use for at least 100 years) and recent blends. The data show that older blends are more likely to be phonesthetically motivated than recent blends. This raises the possibility that longevity may be tied to phonesthetic structure, but no conclusive data is available. The present paper does however provide lexicographic evidence of multidirectional motivation ties in cognitive blends, attesting to the possible role of phonesthetic synonym networks in organising the lexicon. Collecting corpus-based data is the next step towards verifying this claim.

1) Do phonesthemes exist as organising structures in the lexicon? Uncertain, but there is diachronic evidence shows the sporadic existence of multidirectional motivation due to reanalysis of short indefinite blends.

2) Is phonesthetic attraction verifiable lexicographically? The blend reanalysis case studies do not disprove the theory, but do not provide conclusive data. What can be said is there is undeniable evidence of sporadic reanalysis based on soundand-meaning pairings. This confirms the plausibility of Bergen's position that phonesthemes have the ability to 'systematize the lexicon' (Bergen, 2010: 52). However, more accurate tools are required to pursue the study and obtain more accurate measurements and data. If phonesthemes come about and evolve though context and usage - as suggested by the results - , then a context-based data-driven study is required (see Renouf 2013 who demonstrates statistical lexical methods in analysing word life-cycles).

3) Finally, and crucially, in order to pursue this study, how can one measure phonesthetic attraction? New statistical tools show promise for analysing semantic relatedness. Correspondence analysis (Glynn 2014a) and VSM (vector space models) (see Turney \& Pantel 2010) show heuristic potential. As suggested by the results of this paper, frequency (which requires high numbers) may not be the ideal index for measuring phonestheme strength. Instead, the notion of semantic density, using VSM tools, may be able to represent and measure semantic relatedness 
(Otis \& Sagi, 2008 ; Boussidan et al, 2009), and therefore be ideal to test the theory of phonesthetic attraction.

The study of phonesthemes shows thought-provoking avenues of research. The availability of increasingly sophisticated language processing tools and methods (Glynn, 2010, 2014a, 2014b) shows great promise for answering longstanding questions, such as how phonesthemes come about, and how lexical iconicity is structured. The future directions for research opened by this article concern the semantics of phonesthemes, and in particular semantic attraction. Semantic shift can be tested via a diachronic study of a monomorphemes carrying a phonestheme (see Philps (2008a) and (2008b)). Smith (n.d.) focuses on documenting semantic shift in $f l$ - monomorphemes in the OED to identify the sense(s) of the phonestheme $f$-. A historically-sliced corpus-based study must also be developed to produce contextbased diachronic data of semantic shift. At the heart of the matter is developing an adequate scientific method for tracking historical semantic change in order to test the phonesthetic hypothesis accurately.

\section{References}

Abelin, Åsa (1999). Phonesthemes in Swedish. In Proceedings of XIV International Conference of Phonetic Sciences 99. 1333-1336. Berkeley University of California. http://www. ling.gu.se/ abelin/ArtikelnICPhS.pdf (last access 16/08/13).

Abramova, Ekaterina, Raquel Fernandes, \& Frederico Sangati (2013). Automatic labeling of phonesthemic senses. Proceedings of the 35th Annual Cognitive Science Meeting 2013. http:/ / staff.science.uva.nl/ raquel/papers/2013/phonesthemes_cogsci2013.pdf. (last access 05/01/2014).

Ahlner, Felix \& Jordan Zlatev (2010). Cross modal iconicity: A Cognitive Semiotic Approach to Sound Symbolism. Sign Systems Studies 38: 298-348.

Albrespit, Jean (2007). Montrer, cacher: la référence construite par les néologismes. L'envers du décor, 47e Congrès de la SAES, 54-73, Avignon.

Allan, Kathryn (2011). Using OED data as evidence for researching semantic change. Allan, Kathryn \& Justinya Robinson, eds. Current Methods in Historical Semantics. Berlin \& New York: De Gruyter, 17-40.

Argoud, Line (2008). Les 'mots en bl-' du lexique anglais: étude de la structuration des données dans une optique lexico-cognitive. [bl- words in the English lexicon: lexicalcognitive corpus analysis]. Lexis 2: 43-76.

Argoud, Line (2010). Réalité des idéophones anglais (phonesthèmes): propositions dans le cadre d'une approche de linguistique cognitive [the reality of English phonesthemes]. E-rea, Revue d'études sur le monde anglophone. http:/ / erea.revues.org/1301. (last access 16/08/13).

Ayto, John (1999). 20th Century Words. Oxford: Oxford University Press.

Bat-El, Outi (2006). Blend. Brown, E. Keith, ed. Encyclopedia of Language and Linguistics, 2nd edition. Oxford: Elsevier, 2.66-70.

Bauer, Laurie (1983). English Word Formation. Cambridge: Cambridge University Press. 
Benczes, Réka (2010). Setting limits in the production and use of metaphorical and metonymical compounds. Onysko, Alexander \& Sascha Michel, eds. Cognitive Perspectives on Word Formation. Berlin \& New York: De Gruyter, 219-242.

Bergen, Benjamin K. (2004). The psychological reality of phonaesthemes. Language 80.2: 291-311.

Bergen, Benjamin K. (2010). Phonesthemes: Frequency and psychological reality. Paper given at the Emory University Conference workshop. Sound Symbolism: Challenging the Arbitrariness of Language. 26-27 March 2010. http://psychology.emory.edu/ soundsymbolismworkshop2010/Bergen_SoundSymbolism_2010.pdf. (last access 16/08/13).

Bolinger, Dwight L. (1950). Rime, assonance and morpheme analysis. Word 6.2: 117-136.

Bolinger, Dwight L. (1965). Forms of English: Accent, Morpheme, Order. Isamu Abe \& Tetsuya Kanekiyo, eds. Cambridge \& Tokyo: Harvard University Press \& Hokuou.

Bottineau, Didier (2008). The submorphemic conjecture in English: towards a distributed model of the cognitive dynamics of submorphemes. Lexis 2: 19-42.

Boussidan, Armelle, Eyal Sagi, \& Sabine Ploux (2009). Phonaesthemic and Etymological effects on the Distribution of Senses in Statistical Models of Semantics. Proceedings of the 34th Cognitive Science Annual Meeting 2009, 36-40.

Bragdon, Janice (2008). Blends. Manuscript, University of Florida, Gainesville.

De Cuypere, Ludovic (2008). Limiting the iconic: from the metatheoretical foundations to the creative possibilities of iconicity in language. Amsterdam-Philadelphia: John Benjamins.

Drellishak, Scott (2006). Statistical techniques for detecting and validating phonesthemes. LSA Annual Meeting. Anaheim, CA.

Fill, Alwin (2004). Remotivation and reinterpretation. Booij, Geert, Christian Lehmann \& Joachim Mugdan, eds. Morphologie: ein internationales Handbuch zur Flexion und Wortbuildung. Berlin \& New York: De Gruyter, 1615-1625.

Glynn, Dylan (2010). Corpus-driven Cognitive semantics. Introduction to the field. Glynn Dylan \& Kerstin Fischer, eds. Quantitative Methods in Cognitive Semantics. Corpusdriven approaches. Berlin: Mouton de Gruyter, 1-42.

Glynn, Dylan (2014a). Correspondence analysis. An exploratory technique for identifying usage patterns. Glynn, Dylan \& Justyna A. Robinson, eds. Corpus Methods for Semantics. Quantitative Studies in Polysemy and Synonymy. Amsterdam: John Benjamins, 133-179.

Glynn, Dylan (2014b). Techniques and tools. Corpus methods and statistics for semantics. Glynn, Dylan \& Justyna A. Robinson, eds. Corpus Methods for Semantics. Quantitative Studies in Polysemy and Synonymy. Amsterdam: John Benjamins, 307-341.

Gries, Stefan (2004). Isn't that fantabulous? How similarity motivates intentional morphological blends in English. Achard, Michel \& Suzanne Kemmer, eds. Language, Culture, and Mind. Stanford, CA: CSLI, 415-428.

Hock, Hans Heinrich, \& Brian Joseph (2009). Language History, Language Change and Language Relationship: An Introduction to Historical and Comparative Linguistics. Berlin \& New York: De Gruyter. Reprint [1996].

Joseph, Brian (1997). On the linguistics of marginality: the centrality of the periphery. Chicago Linguistic Society Language Arts \& Disciplines. http://www.ling.ohiostate.edu/ bjoseph/publications/1997onth.pdf. (last access 16/08/13).

Katamba, Francis (2005). English Words. London: Routledge. 2nd edition. Reprint [1994].

Kaisse, Ellen M. (2005). Word Formation and Phonology. Štekauer, Pavol \& Rochelle Lieber, eds. Handbook of Word Formation. Dordrecht: Springer, 25-47. 
Kelly, Michael H. (1998). To brunch or to brench: Some aspects of blend structure. Linguistics 36.3: 579-590.

Kemmer, Suzanne (2003). Schemas and lexical blends. Cuyckens, Hubert, Thomas Berg, René Dirven \& Klaus-Uwe Panther, eds. Motivation in Language: Studies in Honour of Günther Radden. Amsterdam: John Benjamins, 69-97.

Kilgariff Adam, \& Pavel Rychly. Sketch Engine, Lexical Computing Limited. https:// the.sketchengine.co.uk/auth/corpora/.

Lehrer, Adrienne (2007). Blendalicious. Munat, Judith, ed. Lexical Creativity, Texts and Contexts. Amsterdam \& Philadelphia: John Benjamins, 115-133.

Luce, Paul A. \& David B. Pisoni (1998). Recognizing spoken words: The neighborhood activation model. Ear and Hearing 19 : 1-36.

Marchand, Hans (1969). The Categories and Types of Present-Day English Word-Formation, A Synchronic-Diachronic Approach. 2nd edition. München: C.H. Beck'sche Verlagsbuchhandlung.

Martin, Andrew (2007). The Evolving Lexicon. PhD dissertation UCLA. Manuscript. http://www.linguistics.ucla.edu/general/dissertations/martin_dissertationucla200 7.pdf. (last access 16/08/13).

Miller, D. Gary (2010). Language Change and Linguistic Theory. 2 vols. Oxford: Oxford University Press.

Miller, D. Gary (2014). Lexicogenesis. Oxford: Oxford University Press.

Ohala, John (1997). Sound Symbolism. Seoul International Conference on Linguistics (SICOL) 4: 98-103.

Onysko, Alexander, \& Sascha Michel (2010). Unravelling the cognitive in word formation. Onysko, Alexander, \& Sascha Michel, eds. Cognitive Perspectives on Word Formation. Berlin \& New York: De Gruyter, 1-25.

Otis, Katya, \& Eyal Sagi (2008). Phonaesthemes: A corpora-based analysis. Love, Bradley, C., Ken McRae, \& Vladimir M. Sloutsky, eds. Proceedings of the 30th Annual Meeting of the Cognitive Science Society. 65-70 Austin, TX: Cognitive Science Society, 65-70.

Philps, Dennis (2008a). Submorphemic iconicity in the lexicon: a diachronic approach to English 'gn' words. Lexis 2: 125-139.

Philps, Dennis (2008b). From mouth to eye. Smith, Andrew D., Kenny Smith, \& Ramon Ferreri Cancho, eds. The Evolution of Language. Singapore: World Scientific Publishing, 251-258.

Pinker, Stephen (2008). The Stuff of Thought: Language as a Window into Human Nature, London: Penguin.

Plag, Ingo (2003). Word-Formation in English. Cambridge: Cambridge University Press.

Ploux, Sabine, Armelle Boussidan, \& Hyungsuk Ji (2010). The Semantic Atlas: an interactive model of lexical representation. Proceedings of the seventh conference of International Language Resources and Evaluation, Valletta, Malta. N. Calzolari, Nicoletta, Khalid Choukri, Bente Maegaard, Joseph Mariani, Jan Odjik, Stelios Piperidis, Mike Rosner, \& Daniel Tapias, eds., European Language Resources Association (ELRA).

Ploux, Sabine. The Semantic Atlas. Institut des Sciences Cognitives, CNRS - University Lyon 1 - UMR 5015. http://dico.isc.cnrs.fr/dico/en/search. (last access January 2014).

Pound, Louise (1914). Blends, their relation to English word formation. Anglistische Forschungen 42: 1-58.

Quinion, Michael (1996). Through The Blender http://www.worldwidewords.org/ articles/blend.htm. (last access 16/08/13). 
Reay, Irene Elizabeth (2009). Sound symbolism. Allan, Keith, ed. Concise Encyclopedia of Semantics. Oxford: Elsevier, 893-901. Reprint [1994].

Renouf, Antoinette (2013). A finer definition of neology English: the life-cycle of a word. In Hasselgard, Hilde, Jarle Ebeling \& Signe Oksefjell Ebeling (eds.), Corpus Perspectives on Patterns of Lexis, 177-208. Amsterdam: John Benjamins.

Smith, Chris (nd). Tracking historical semantic shift in fl-monomorphemes in the OED. MS.

Štekauer, Pavol \& Rochelle Lieber, eds. (2005). Handbook of Word-Formation. Dordrecht: Springer.

Szymanek, Bogdan (2005). The latest trends in English word-formation. Štekauer, Pavol \& Rochelle Lieber, eds. Handbook of Word-Formation. Dordrecht: Springer, 429-448.

Tournier, Jean (2007). Introduction descriptive à la lexicogénétique de l'anglais contemporain. Paris \& Geneva: Champion-Slatkine. Reprint [1985].

Turney, Peter D., \& Patrick Pantel (2010). From frequency to meaning: Vector Space Models of semantics. Journal of Artificial Intelligence Research 37 : 141-188.

Umbreit, Birgit (2010). Does love come from to love or to love from love? Why lexical motivation has to be regarded as bidirectional. Cognitive Perspectives on Word Formation, Onysko, Alexander, \& Sascha Michel (eds.), 301-333. Berlin/ New York: Walter de Gruyter.

Veale, Tony \& Cristina Butnariu (2010). Harvesting and understanding on-line neologisms. Onysko, Alexander, \& Sascha Michel, eds. Cognitive Perspectives on Word Formation,.Berlin \& New York: Walter de Gruyter, 399-420.

Waugh, Linda R. (1979). On the sound shape of language. Jakobson, Roman \& Linda R. Waugh, eds. The Sound Shape of Language. Bloomington, Ind. \& London: Indiana University Press \& Harvester, 198-214.

Waugh, Linda R. (1994). Degrees of iconicity. Journal of Pragmatics 22 : 55-70.

\section{Dictionaries}

The Oxford English Dictionary (2013) online subscription version, 3 3 rd edition. Oxford: Oxford University Press. http://www.oed.com/ (last access 2/01/2014).

Oxford English Corpus (2013) provided by Sketch Engine. Oxford: Oxford University Press.

McMillan Dictionary online (2009-2013). McMillan Publishers Limited. http:// www.macmillandictionary.com/.

Merriam-Webster online Dictionary (2014). Encyclopedia Britannica Company. http:// www.merriam-webster.com/.

Concise Oxford English Dictionary online (2013). Oxford: Oxford University Press.

Urban Dictionary online (1999-2014). http:/ / www.urbandictionary.com/.

Received February 3, 2015

Accepted for publication March 2, 2015 
Author's address:

135 avenue Pierre Brossolette, apt 19, 92120 Montrouge, France.

chris.smith@unicaen.fr 


\section{Appendix A: Phonesthetic network in 42 older blends classified by onset}

\begin{tabular}{|c|c|c|c|c|}
\hline BLEND & date & onset & rhyme/coda & synonym network \\
\hline bumble & 1532 & b- & -umble & bungle, jumble, fumble \\
\hline bash & 1790 & b- & -ash & $\begin{array}{l}\text { beat bang } \\
\text { dash, gash, gnash, hash, } \\
\text { lash, pash, smash, clash }\end{array}$ \\
\hline boost v & 1815 & b- & -oost & $\begin{array}{l}\text { boom } \\
\text { hoist, boist }\end{array}$ \\
\hline burble & 1300 & b- & -urble & $\begin{array}{l}\text { bubble } \\
\text { purl } \\
\text { murmur }\end{array}$ \\
\hline blotch & 1604 & bl- & -otch & $\begin{array}{l}\text { blast } 1300 \\
\text { botch }\end{array}$ \\
\hline blurt & 1611 & bl- & -urt & $\begin{array}{l}\text { blow, blast, blash } \\
\text { spurt, squirt. }\end{array}$ \\
\hline brunch & 1896 & br- & -unch & breakfast lunch \\
\hline chortle & 1871 & ch- & -ortle & $\begin{array}{l}\text { chuckle } \\
\text { snort }\end{array}$ \\
\hline flaunt & 1566 & fl- & -aunt & $\begin{array}{l}\text { fly, flout } \\
\text { vaunt }\end{array}$ \\
\hline flounder & 1592 & fl- & -ounder & $\begin{array}{l}\text { blunder } \\
\text { flounce } 1542\end{array}$ \\
\hline flurry & 1698 & fl- & -urry & $\begin{array}{l}\text { flaw } \\
\text { hurry }\end{array}$ \\
\hline flush & 1300 & fl- & -ush & $\begin{array}{l}\text { fly, flutter } \\
\text { rush }\end{array}$ \\
\hline flare & 1550 & fl- & -are & $\begin{array}{l}\text { flame } \\
\text { glare }\end{array}$ \\
\hline flustrate & 1712 & fl- & -ustrate & $\begin{array}{l}\text { fluster, flurry } \\
\text { frustrate }\end{array}$ \\
\hline fluff & 1790 & fl- & -uff & $\begin{array}{l}\text { flue } \\
\text { puff, }\end{array}$ \\
\hline flimmer & 1880 & fl- & -immer & $\begin{array}{l}\text { flicker } \\
\text { glimmer }\end{array}$ \\
\hline glaze & 1616 & gl- & -aze & glance, glare, glimpse \\
\hline
\end{tabular}




\begin{tabular}{|c|c|c|c|c|}
\hline glob & 1900 & gl- & $-o b$ & glide, gleam \\
\hline grumble & 1608 & gr- & -umble & $\begin{array}{l}\text { groan, grunt } \\
\text { mumble, rumble }\end{array}$ \\
\hline mimsy & 1871 & m- & -imsy & flimsy \\
\hline prance & & pr- & -ance & $\begin{array}{l}\text { prank, proud } \\
\text { dance }\end{array}$ \\
\hline prissy & 1842 & pr- & -issy & sissy \\
\hline quag & 1598 & $q u-$ & $-a g$ & $\begin{array}{l}\text { quake } \\
\text { bog }\end{array}$ \\
\hline scrouge & 1755 & scr- & -ouge & $\begin{array}{l}\text { screw } \\
\text { gouge }\end{array}$ \\
\hline scrunch & 1825 & scr- & -unch & crunch \\
\hline scrumptious & 1836 & scr- & -umptious & $\begin{array}{l}\text { scrunch } \\
\text { sumptuous }\end{array}$ \\
\hline slosh & 1808 & sl- & -osh & $\begin{array}{l}\text { slop } \\
\text { slush }\end{array}$ \\
\hline slithy & 1871 & sl- & -ithy & slide slime slink sleek \\
\hline smash & 1699 & sm- & -ash & $\begin{array}{l}\text { smack } \\
\text { bash }\end{array}$ \\
\hline smarm & 1847 & sm- & -arm & $\begin{array}{l}\text { smear } \\
\text { charm }\end{array}$ \\
\hline smog & 1884 & sm- & $-o g$ & smear smut \\
\hline sniggle & 1815 & sn- & -iggle & $\begin{array}{l}\text { snicker } \\
\text { giggle }\end{array}$ \\
\hline snark & 1876 & sn- & -ark & snork, snark, snore \\
\hline snooze & 1789 & sn- & -ooze & $\begin{array}{l}\text { sleep } \\
\text { nap } \\
\text { doze }\end{array}$ \\
\hline splutter & 1677 & spl- & -utter & $\begin{array}{l}\text { sputter } \\
\text { splash }\end{array}$ \\
\hline splatter & 1787 & spl- & -atter & $\begin{array}{l}\text { spatter } \\
\text { splash }\end{array}$ \\
\hline squish & 1647 & squ- & -ish & $\begin{array}{l}\text { squash } 1565 \text {, squeeze } \\
\text { squiss }\end{array}$ \\
\hline squiggle & 1804 & squ- & -iggle & $\begin{array}{l}\text { wriggle } \\
\text { squirm }\end{array}$ \\
\hline squirl & 1843 & squ- & -irl & twirl whirl squirt squish \\
\hline swizzle & 1813 & sw- & -izzle & $\begin{array}{l}\text { swill } \\
\text { guzzle }\end{array}$ \\
\hline
\end{tabular}




\begin{tabular}{|l|l|l|l|l|} 
swipe & 1829 & sw- & -ipe & $\begin{array}{l}\text { sweep } \\
\text { wipe }\end{array}$ \\
\hline thwack & 1533 & thw- & -ack & $\begin{array}{l}\text { thack, thump } \\
\text { thw- }\end{array}$ \\
\hline trudge & 1547 & tr- & -udge & $\begin{array}{l}\text { trot } \\
\text { drudge }\end{array}$ \\
\hline twiddle & 1547 & tw- & -iddle & $\begin{array}{l}\text { twist } \\
\text { fiddle, piddle }\end{array}$ \\
\hline twirl & 1598 & tw- & -irl & $\begin{array}{l}\text { twist } \\
\text { whirl }\end{array}$ \\
\hline & & & & $\begin{array}{l}\text { twist } \\
\text { fizzle, swizzle (-le } \\
\left.\text { suffix }{ }^{12}\right)\end{array}$ \\
twizzle & 1825 & tw- & -izzle11 & $\begin{array}{l}\text { bang, } \\
\text { whack }\end{array}$ \\
\hline whang & & & & \\
\hline
\end{tabular}

11 Miller 2014: 'Anderson (1998: 128) discusses words in -izzle that "connote the sound of liquid on a surface": pizzle [1486] 'animal penis', mizzle [1490] 'fine misty rain', drizzle [1543], sizzle [1603], swizzle [1813], frizzle [1839] 'sputter while frying', fizzle [1859] 'sputter'.'

12 'Verbal formative with a frequentative or sometimes a diminutive sense.' The OED online, 2012. 


\section{Appendix B: List of 285 blends (cognitive and morphological) by date (all dates are from the $O E D$ unless specifically stated otherwise)}

scorn [1200] (scoff x spurn)

stumble [1325] (stop $x$ tumble)

shatter [1330] (shake $x$ shatter)

prance [1380] (prance $x$ dance)

quaver [1439] (quake $x$ waver)

blatterature [1512] (blabber / blather $x$

literature)

clash [1522] (clap $\mathrm{x}$ dash)

bumble [1532] (bungle $x$ stumble)

thwack [1533] ( thrash $x$ whack)

squench [1535] (slake $x$ quench)

foist [1545/1570] (fist $x$ hoist)

trudge [1547] (trot $x$ drudge)

twiddle [1547] (twist $x$ fiddle)

flush [1548] (flash/flare $x$ blush)

flare [1550] (flame $x$ glare)

flaunt [1566] (fly, flout $x$ vaunt)

scurry [1580] (skirr, scour $x$ hurry)

quag [1589] (quaking $x$ bog)

flounder [1592] (founder $x$ blunder)

twirl [1598] (tirl $x$ whirl)

blotch [1604] (blot x splotch/botch)

grumble [1608] (grommeler/grunt $x$ rumble)

blurt [1611] (blow/blare x spurt)

glaze [1616] (gaze $x$ glare)

squish [1647] (squirt $x$ swish)

dumbfound [1653] (dumb x confound)

splutter [1677] (splash $\mathrm{x}$ sputter)

whang [1684] (whack $x$ bang)

flurry [1698] (flaw $x$ hurry)

smash [1699] (smack $x$ bash) (note new sense 1708)

flustrat(ed) [1712] (fluster $x$ frustrat(ed))

cantankerous [1736] (contentious $x$

rankerous/cankerous) scrouge [1755] (screw $x$ gouge)

flabbergast [1772] (flabby/flap x aghast)

splatter [1787] (splash $x$ spatter)

snooze [1789] (sleep $x$ nap $x$ doze)

fluff [1790] (flue $x$ puff)

bash [1790] (beat $x$ dash)

prisonscape [1796] (prison $x$ landscape)

squiggle [1804] (squirm $x$

wriggle/wiggle)

slosh [1808] (slop x slush)

gerrymander [1812] (Gerry x salamander)

doldrums [1812] (dull $x$ tantrums)

swizzle [1813/1847v] (swill $x$ fizzle)

sniggle [1815] (snicker $x$ giggle)

boost [1815] (boom $x$ hoist)

plop [1821] (plunge $x$ flop)

twizzle [1825] (twist $x$ swizzle/drizzle)

scrunch [1825] (squeeze $x$ crunch)

contraption [1825] (contrivance $x$ trap $x$

conception)

swipe [1829] (sweep $x$ wipe)

scrumptious [1836] (scrimp $\mathrm{x}$ delicious)

flummox [1837] (flump x hummock)

permafrost [1838] (permanent $x$ frost)

prissy [1842] (prim x sissy)

burble [1843] (murmur x bubble)/

(bubble x purl)

squirl [1843] (squiggle $x$ twirl/whirl)

Eurasian [1844] (Europe $x$ Asian)

bodacious [1845] (bold $x$ audacious)

boldacious [1845] (bold $x$ audacious)

squattocracy [1846] (squat $x$ aristocracy)

smarm [1847] (smear x charm)

bit [1848] (binary $x$ digit)

snivelization [1849] (snivel $x$ civilization)

Oxbridge [1849] (Oxford x Cambridge) 
Camford [1850] (Cambridge $x$ Oxford) dextrose [1869] (dextrorotary $x$ glucose) slithy [1871] (slimy $x$ lithe) mimsy [1871] (miserable $x$ flimsy) chortle [1871] (chuckle $x$ snort) snark [1876] (snake $x$ shark) slanguage [1879] (slang $x$ language) flimmer [1880] (flicker $x$ glimmer) penultimatum [1882] (penultimate $x$ ultimatum) smog [1884 MW] (smoke $x$ fog) electrocute [1889] (electric $x$ execute) cattalo [1889] (cattle $x$ buffalo) shamateur [1896] (sham $x$ amateur) brunch [1896] (breakfast $x$ lunch) happenstance [1897] (happen $x$ circumstance)

Amerindian [1899] (American x Indian) glob [1900] (blob x gob)

canoodle [1900] (canoe $x$ paddle) travelogue [1903] (travel $x$ catalogue) plumcot [1903] (plum $x$ apricot) tangelo [1904] (tangerine $x$ pomelo) flub [1904 MW] (fluff $x$ blub) dramedy [1905] (drama x comedy) Bakerloo [1906] (Baker street x Waterloo) blurb [1907] (blurt x burble) spork [1909] (spoon $x$ fork) mingy [1911] (mean x stingy)

Chunnel [1914] (Channel $x$ tunnel) advertorial [1914] (advertisement $x$ editorial)

absotively [1914] (absolutely x positively) posilutely [1914] (positively $x$ absolutely) rurban [1915] (rural x urban) scientifiction [1916] (science $x$ fiction) umpteen [1918] (ump $x$ teen) goon [1921] (gorilla $x$ baboon) sexploitation [1924] (sexual x exploitation)

sexpert [1924] (sex x expert)

motel [1925] (motor $x$ hotel)

greige [1926] (grey $x$ beige)

tigon [1927] (tiger $x$ lion)

sexationalism [1927] (sex x

sensationalism)

palimony [1927] (pal x alimony)

sexational [1928] (sex $x$ sensational)

ambisextrous [1929] (ambidextrous $x$ sex)

walkathon [1930] (walk x marathon)

snazzy [1931] (snappy x jazzy)

bonk [1931] (bang/ bump x conk)

futz [1932] (fuck x putz)

applelicious [1933] (apple $x$ delicious)

positron [1933] (positive $x$ electron)

Jacobethan [1933] (Jacobean $x$

Elizabethan)

mocktail [1936] (mock x cocktail)

meld [1936] (melt $x$ weld)

guestimate [1936] (guess $x$ estimate)

spam [1937] (spiced $x$ ham)

liger [1938] (lion $x$ tiger)

celebutante [1939] (celebrity $x$ debutante)

tween [1941] (between $x$ teen)

icecapade [1941] (ice $x$ escapade)

happenchance [1941] (happenstance $x$ chance)

squillion [1943] (squeal ? x million)

zillion [1944] (z x million)

sheeple [1945] (sheep x people)

transistor [1948] (transfer $x$ resistor)

ginormous [1948] (gigantic $x$ enormous)

dixiecrat [1948] (Dixie $x$ democrat)

fanzine [1949] (fan x magazine)

coca-colonization [1950] (Coca-Cola x colonization)

skort(s) [1951 Miller] (skirt x shorts) 
smaze [1953] (smoke $x$ haze)

privilgentsia [1953] (privilege $x$

intelligentsia)

Medicare [1953] (medical x care)

frenemy [1953] (friend $x$ enemy)

bleep [1953] (blank $x$ beep)

droodle [1953 Wiki] (drawing $\mathrm{x}$ riddle $\mathrm{x}$ doodle)

vodkatini [1955] (vodka x martini)

glitterati [1956] (glitter $x$ literati)

muppet [1959] (marionnet x puppet)

motown [1959] (motor $x$ town)

fantabulous [1959] (fantastic $x$ fabulous)

sexploit [1960] (sex x exploit)

Breathalyz/ser [1960] (breath $x$ analyser)

bionics [1960] (biology $x$ electronics)

kidult [1960] (kid $x$ adult)

glamazon [1960 COED] (glamour x amazon)

docudrama [1961] (documentary x drama)

slurb [1962] (slum x suburb)

quasar [1964] (quasi x stellar)

stoup [n/a in Miller 2014] (stew x soup)

stagflation [1965] (stagnation $\mathrm{x}$ inflation)

mockumentary [1965] (mock x

documentary)

Spanglish [1967] (Spanish x English)

humongous [1967] (huge $x$ monstrous)

dancercise [1967] (dance $x$ exercise)

workaholic [1968] (work x alcoholic)

Nixonomics [1969] (Nixon $x$ exonomics)

shoat [1969] (sheep x goat)

Reagonomics [1970] (Reagan x

economics)

animatronics [1971] (animation $x$

electronics)

phreak [1971] (phone $x$ freak)

geep [1971] (goat $x$ sheep) blaxploitation [1972] (black x exploitation)

funtastic [1972 in Miller] (fun x fantastic)

televangelist [1973] (television $x$

evangelist)

slumpflation [1974] (slump $x$ inflation)

beefalo [1974] (beef $x$ buffalo)

bling [1974 UD] (blast $x$ ring)

wuss [1977] (wimp x puss)

fembot [1976] (female $x$ robot)

Britpop [1977] (British x pop)

cineplex [1978] (cinema x complex)

affluenza [1979] (affluence $x$ influenza)

docusoap [1979] (documentary x soap)

infotainment [1980] (information $x$

entertainment)

twonk [n/a] (twat x plonker)

broasted [1980 COED] (broiled $x$ roasted) tanorexia [1980 COED] ( $\tan x$ anorexia)

dongle [1981] (dangle $x$ port)

strippagram [1981] (stripper $x$ telegram)

informercial [1981] (information $x$

commercial)

wussy [1981] (wuss x pussy)

pleather [1982] (plastic $x$ leather)

camcorder [1982] (camera $x$ recorder)

Swatch [1983] (Swiss $x$ watch)

fuzzword [1983] (fuzz x buzzword)

shopaholic [1984] (shop $x$ alcoholic)

guppie [1984] (gay x yuppie)

tankini [1985] (tank top $\mathrm{x}$ bikini)

Pictionary $[\mathrm{n} / \mathrm{a}]$ (picture $\mathrm{x}$ dictionary)

phishing [1987??] (phreaking $x$ fishing)

vog [1987 MW] (volcano x smog)

dallymony [1987 MW] (dalliance $x$

alimony)

swaption [1988] (swap x option)

gaydar [1988] (gay x radar)

pluot [1988] (plum $x$ apricot) 
snuba [1989??] (snorkel x snuba)

emoticon [1990] (emotion $x$ icon)

malware [1990] (malicious $x$ software)

moobs [1990 COED] (man $x$ boobs)

carjacking [1991] (car $x$ hijacking)

babelicious [1991] (babe $x$ delicious)

trustafarian [1992] (trustfund $x$

rastafarian)

netizen [1993] (net $x$ citizen)

webzine [1994] (web x magazine)

metrosexual [1994] (metropolitan x

heterosexual)

webliography [1995] (web x

bibliography)

twigloo [1995] (twig $x$ igloo)

hacktivist [1995] (hacker $x$ activist)

scratchiti [1995] (scratch $x$ grafiti)

bridezilla [1995] (bride x Godzilla)

alcopop [1995] (alcoholic x pop)

screenager [1996] (screen $x$ teenager)

adultescent [1996] (adult $x$ adolescent)

babymoon [1996?] (baby x honeymoon)

webisode [n/a] (web $x$ episode)

webinar [1997] (web x seminar)

intermercial [1997] (interlude $x$

commercial)

Californication [1997] (California x fornication)

splurgundy [1998] (splurge x burgundy)

blog [1999] (web x log)

chillax [1999 MW] (chill $x$ relax)

treggings [2000 COED] (trouser $x$

leggings)

manbag [2000 COED] (man $x$ handbag) jeggings [2000 COED] (jeans $x$ leggings)

Wikipedia [2001?] (wiki x encyclopedia)

spim [2002?] (spam x I.M.)

cankle [2002?] (calf $x$ ankle)

vlog [2002?] (video $x$ blog) staycation [2003] (stay (at home) x vacation)

Chrismukkah [2003 UD] (Christmas x Hannukah)

intexticated [2003 UD] (intoxicated x texting)

brifter [2003?] (brake $x$ shift $x$ lever)

bacne [2003 UD] (back $x$ acne)

manscaping [2003 COED] (man $x$

landscaping)

bromance [2004 MW] (bro x romance)

podcast [2004] (iPod $x$ broadcast)

splog [2005 CNET] (blog x spam)

sexting [2005 Wiki] (sex $x$ texting)

guyliner [2005 UD] (guy $x$ eyeliner)

Fictionarium [2005?] (fiction $x$ aquarium)

manny [2006 UD] (male $x$ nanny)

freemium [2006 Wiki] (free $x$ premium)

snitzy [2007] (snazzy x ritzy)

pob [2007?] (Posh $x$ bob)

trampede [2007 UD] (tramp x stampede)

twitterati [n/a] (Twitter $x$ literati)

googleganger [2007 McM] (Google $x$

doppleganger)

manjoyment [2007 UD] (man x

enjoyment)

choup [2007?] (chowder $x$ soup)

fauxmance [2008] (faux $x$ romance)

showmance [2008] (show $x$ romance)

wogging [2008] (walk $x$ jogging)

glamping [2008 NYT] (glamour $x$

camping)

snowmageddon [2008 UD] (snow x

armageddon)

Groupon [2008 Wiki] (group x coupon) mancession [2009 NYT] (man $x$ recession)

vook [2009 NYT] (video $x$ book)

twincest [2009?] (twin $\mathrm{x}$ incest)

recessionista [2010 COED] (recession $x$ fashionista) 
thinspiration [2011?] (thin $\mathrm{x}$ inspiration)

fitspiration $[\mathrm{n} / \mathrm{a}]$ (fit $\mathrm{x}$ inspiration)

smize [2012?] (smile $x$ eyes)

Grexit [2012?] (Greek x exit)

tweetheart [2010 COED] (tweet $x$

sweetheart)

Frappuccino $[\mathrm{n} / \mathrm{a}]$ (frappé $\mathrm{x}$ capuccino)

Craisin $[\mathrm{n} / \mathrm{a}]$ (cranberry $\mathrm{x}$ raisin)

skinoe $[\mathrm{n} / \mathrm{a}]$ (ski $\mathrm{x}$ canoe)

tottle $[\mathrm{n} / \mathrm{a}]$ (tube $\mathrm{x}$ bottle)

swacket [n/a] (sweater $x$ jacket)

snizzle $[\mathrm{n} / \mathrm{a}]$ (snow $\mathrm{x}$ drizzle) snausage $[\mathrm{n} / \mathrm{a}]$ (snack $\mathrm{x}$ sausage)

slopportunity [n/a] (sloppy $x$

opportunity)

shopportunity [n/a] (shop $\mathrm{x}$

opportunity)

manorexia [n/a] (man $x$ anorexia)

limon [n/a] (lime $x$ lemon)

hott [n/a] (hot x OTT)

clandestiny $[\mathrm{n} / \mathrm{a}]$ (clandestine $\mathrm{x}$ destiny)

Brangelina [n/a] (Brad $x$ Angelina)

Blairista [n/a] (Blair $x$ Sandinista)

manscara [n/a] (man $x$ mascara) 